\section{Combination of Toprimate and Empagliflozin is Considered a Good Option for Treatment of Obesity}

\author{
Younis $\mathbf{M}^{*}$ \\ Consultant, Kafr Elshaikh General Hospital, Egypt Ministry of Health, Egypt
}

Keywords: Combination Therapy; Empagliflozine; Obesity; Topiramine

\section{Introduction}

The incidence of obesity has raised very much in the latest decades in which more than $30 \%$ of peoples are considered obese [1]. Obesity is defined as exaggerated fat that is deposited abnormally in tissues and make health hazards, promoting adipose tissue dysfunction. Guidelines state that the normal body mass index is from 18.5 to $24.9, \mathrm{BMI}$ from $=25 \mathrm{~kg} / \mathrm{m}^{2}$ to $29.9 \mathrm{~kg} / \mathrm{m}^{2}$ is known to be overweight, $\mathrm{BMI}=30 \mathrm{~kg} / \mathrm{m}^{2}$ known to be obese. The body mass index (BMI) is a value extracted from (weight) and height of a person [2]. Obesity is considered a disease that is generated from many factors affecting energy balance, as input is more than the output, which is transformed into triglycerides making fat cells larger in size causing an increase in weight [3].

It is evidenced that genetics has a great impact on obesity occurrence; all in all, the risk of getting obesity in the future is linked to many factors like sedentary lifestyle, type of diet [4]. One of the most important factors determining obesity risk is genetics [5]. It's is now known that body mass index is hereditable in $25-40 \%$. But there must be environmental factors with genetics for obesity to occur [6]. Researchers consider Basal metabolic rate (which is energy loss during rest) as a possible cause of obesity, as it is considered that obese persons have a low basal metabolic rate. It is a great target to act to treat

*Corresponding author: Younis M, Consultant, Kafr Elshaikh General Hospital, Egypt Ministry of Health, Egypt, Email: ymodmenna@gmail.com

Citation: Younis M (2019) Combination of Toprimate and Empagliflozin is considered a Good Option for Treatment of Obesity. J Transl Sci Res 2: 007.

Received: July 08, 2019; Accepted: December 10, 2019; Published: December 17,2019

Copyright: (c) 2019 Younis M. This is an open-access article distributed unde the terms of the Creative Commons Attribution License, which permits unrestricted use, distribution, and reproduction in any medium, provided the original author and source are credited. obesity and to decrease the occurrence of diseases related to obesity like cardiovascular diseases, type 2 diabetes, and fatty liver. and it is considered a priority of WHO to control obesity prevalence. It is well known that obesity due to an imbalance between calories input and output [7]. And current obesity treatment based on decreasing calorie input and increasing calorie output which is unsuccessful in most cases [8]. Many research papers discussing obesity causes and ways of treatment, discussing the role of the brain in determining the desire for food, and the role of git, liver and fat cells hormones in appetite regulation by affecting the hypothalamus [9].

In fact, due to the nature of obesity which leads to impairment of homeostatic mechanisms leading to an inability to maintain a normal weight, obesity is considered as a chronic disease. And so obesity cannot be managed by short term therapy [10]. Due to the complex nature and overlapping factors in obesity pathogenesis, treatment available now is non-compatible with most causes of obesity which result often by the interaction between the environmental factors and the person genetics [11]. Until this moment, the drugs approved by the FDA for treating obesity act to reduce appetite by affecting satiety centers like phentermine / topiramate and lorcaserin, and by decreasing fat absorption like orlistat. We must put in mind that the efficiency of most of these drugs are $3-7 \%$ weight loss [12].

Now there are a group of new antidiabetic drugs known as sodium-glucose co transporter 2 inhibitors, which lead to reasonable control of blood glucose, and blood pressure and a great decrease in body weight. This group has an unparalleled feature in which it leads to a great decrease in visceral fat than subcutaneous fat [13]. Normally, the kidney can filter about $180 \mathrm{~g} /$ day of glucose which occurs in the proximal convoluted tubule.SGLT2 is responsible for about $90 \%$ reabsorbed glucose [14]. Empagliflozin is the most selective sglt2 inhibitor, which leads to urinary glucose excretion depending on the dose, urinary glucose excretion may reach 90 gram per day [15].

Empagliflozin is approved for managing adults with T2D [16]. Aside from decreasing blood glucose, empagliflozin can lead to a reduction of weight due to the loss of calories by excretion of glucose [17]. Empagliflozin inhibit urinary glucose reabsorption, in which 10 mg of empagliflozin can prevent absorption of about $40 \%$ of glucose increasing with dose to $90 \mathrm{~g}$ of glucose. With the use of empagliflozin in non-diabetic persons, no decrease in blood glucose level, because of the liver increase glucose production Empagliflozin is a well-tolerated drug but with an inconsiderable occurrence of genital infections, and no increase in frequency in urinary tract infections [18].

Topiramate is a drug used for the treatment of convulsions and migraine. topiramate is known to decrease appetite and so used off-label for obesity [19]. Topiramate is used for migraine by a dose of $100 \mathrm{mg}$ and by a dose up to $400 \mathrm{mg}$ for epilepsy and in combination with pheniramine for obesity by a dose from 23 to $90 \mathrm{mg}$ [20]. Topiramate is a drug that is detected in 1979 as an anticonvulsant with $t$ half of about 30 hours and leads to debates and disputes and is used for the treatment of obesity [21]. There are many types of research 
discussing the role of topiramate in the treatment of many diseases like binge eating disorder [22] and post-traumatic stress disorder [23] Research papers also discuss the wieght reducing effect of topiramate and demonstrated that this effect is dependent on the dose of the drugand duration of treatment [24]. Topiramate is a drug that is known to have anti impulsive behavior effect [25]. In one study topiramate given to mouses led to a decrease in body fat and decreased food intake with the increasing metabolic rate [26], with decreasing lipoprotein lipase activity [27]. And in a clinical trial in patients with epilepsy taking topiramate, the patient's weights decrease in the early period of treatment with 2 to $5 \%$ decrease in weight, weight loss increase by 18 months of treatment [28].

\section{Materials and Methods}

The results show that both topiramate and Empagliflozine have weight loss effect if used alone with significant $p$ value which iss 0.0480 with topiramate and 0.0048 in empagliflozine and the greatest weight loss effect if used in combination with $p$ value less than 0.0001 .4 groups of patients with obesity had been monitored in a private clinic, each group 50 patients number, with 35 females and 15 males after written consent from all patients. The ages of all patients were between 30 and 55 years. weights of all patients were between 90 to $160 \mathrm{~kg}$. All patients participating in this trial are asked to have a diet regimen all the time of the trial.

\section{Inclusion criteria}

1. Stable weight in the previous 6 months

2. A sedentary lifestyle

3. No history of diabetes mellitus

4. Taking medication that affects appetite, or weight within the past 6 months

\section{Exclusion criteria}

1. Severe anemia

2. Hypothyroidism and hyperthyroidism

3. Diabetes mellitus

4. Moderate to severe liver or kidney disease

5. Body mass index less than 30

The first group patients received topiramate $25 \mathrm{mg}$ twice daily for 6 months, the second group received empagliflozin $10 \mathrm{mg}$ once daily, the third group patients received topiramate $25 \mathrm{mg}$ twice daily and empagliflozin $10 \mathrm{mg}$ once daily, the fourth group received placebo for 6 months during the period of treatment, we followed the patients and if there were side effects of the drugs used no side effects were monitored during the period of treatment.

\section{Results}

We compared each group with the placebo group after 6 months of treatment. For analysis of data, we used the unpaired-test (Tables $1-4)$.

\begin{tabular}{|c|c|c|c|c|c|c|c|c|c|}
\hline \multirow{2}{*}{\multicolumn{2}{|c|}{$\begin{array}{l}\text { Toble formot: } \\
\text { Grouped }\end{array}$}} & \multicolumn{2}{|c|}{ Group $A$} & \multicolumn{2}{|c|}{ Group 8} & \multirow{2}{*}{\multicolumn{2}{|c|}{$\begin{array}{l}\text { Group C } \\
\text { both drugs }\end{array}$}} & \multirow{2}{*}{\multicolumn{2}{|c|}{$\begin{array}{l}\text { Group D } \\
\text { placebo }\end{array}$}} \\
\hline & & \multicolumn{2}{|c|}{ topiramate } & \multicolumn{2}{|c|}{ empagliflozine } & & & & \\
\hline & & before & after & before & after & before & after & before & after \\
\hline 1 & Title & 90 & 79 & 89 & 74 & 88 & 67 & 90 & 89 \\
\hline 2 & Title & 92 & 80 & 90 & 76 & 90 & 69 & 92 & 92 \\
\hline 3 & Title & 93 & 75 & 92 & 78 & 91 & 70 & 93 & 90 \\
\hline 4 & Title & 96 & 81 & 93 & 78 & 92 & 70 & 96 & 95 \\
\hline 5 & Title & 98 & 85 & 94 & 79 & 94 & 71 & 90 & 89 \\
\hline 6 & Title & 100 & 81 & 96 & 81 & 95 & 72 & 92 & 93 \\
\hline 7 & Title & 101 & 83 & 97 & 81 & 96 & 72 & 94 & 84 \\
\hline 8 & Title & 103 & 78 & 98 & 83 & 97 & 74 & 96 & 95 \\
\hline 9 & Title & 104 & 82 & 100 & 84 & 99 & 77 & 98 & 99 \\
\hline 10 & Title & 105 & 86 & 102 & 86 & 100 & 78 & 100 & 102 \\
\hline 11 & Title & 108 & 90 & 103 & 88 & 101 & 78 & 101 & 103 \\
\hline 12 & Title & 109 & 94 & 104 & 88 & 102 & 78 & 103 & 102 \\
\hline 13 & Title & 111 & 93 & 106 & 91 & 104 & 80 & 105 & 106 \\
\hline 14 & Title & 112 & 88 & 108 & 93 & 105 & 81 & 107 & 108 \\
\hline 15 & Title & 114 & 97 & 109 & 93 & 107 & 83 & 109 & 108 \\
\hline 16 & Title & 115 & 99 & 110 & 96 & 108 & 83 & 111 & 110 \\
\hline 17 & Title & 117 & 97 & 113 & 100 & 109 & 85 & 113 & 115 \\
\hline 18 & Title & 118 & 100 & 114 & 100 & 111 & 85 & 115 & 116 \\
\hline 19 & Title & 119 & 101 & 115 & 99 & 112 & 87 & \begin{tabular}{|c|}
117 \\
\end{tabular} & 119 \\
\hline 20 & Title & 120 & 98 & 117 & 102 & 114 & 88 & 119 & 120 \\
\hline 21 & Title & 122 & 103 & 118 & 101 & 116 & 90 & 120 & 122 \\
\hline
\end{tabular}




\begin{tabular}{|c|c|c|c|c|c|c|c|c|c|}
\hline 22 & Title & 123 & 108 & 119 & 104 & 117 & 94 & 122 & 121 \\
\hline 23 & Title & 125 & 111 & 121 & 6 & 119 & 94 & 123 & 124 \\
\hline 24 & Title & 126 & 109 & 122 & 106 & 121 & 96 & 125 & 126 \\
\hline 25 & Title & 127 & 115 & 123 & 105 & 123 & 96 & 127 & 127 \\
\hline 26 & Title & 129 & 113 & 124 & 107 & 125 & 98 & 129 & 126 \\
\hline 27 & Title & 130 & 108 & 125 & 109 & 126 & 99 & 130 & 128 \\
\hline 28 & Title & 131 & 110 & 127 & 110 & 128 & 100 & 131 & 130 \\
\hline 29 & Title & 133 & 117 & 128 & 110 & 129 & 100 & 133 & 133 \\
\hline 30 & Title & 135 & 120 & 130 & 116 & 130 & 102 & 135 & 136 \\
\hline 31 & Title & 136 & 115 & 131 & 115 & 131 & 104 & 136 & 135 \\
\hline 32 & Title & 137 & 106 & 132 & 117 & 132 & 103 & 137 & 139 \\
\hline 33 & Title & 139 & 121 & 133 & 115 & 134 & 107 & 139 & 138 \\
\hline 34 & Title & 140 & 115 & 136 & 120 & 135 & 105 & 140 & 140 \\
\hline 35 & Title & 141 & 121 & 138 & 123 & 137 & 108 & 141 & 140 \\
\hline 36 & Title & 142 & 119 & 139 & 121 & 138 & 108 & 142 & 138 \\
\hline 37 & Title & 144 & 119 & 140 & 120 & 140 & 110 & 144 & 140 \\
\hline 38 & Title & 146 & 123 & 141 & 125 & 141 & 110 & 146 & 144 \\
\hline 39 & Title & 147 & 126 & 142 & 122 & 143 & 112 & 147 & 148 \\
\hline 40 & Title & 149 & 119 & 143 & 125 & 144 & 113 & 149 & 149 \\
\hline 41 & Title & 150 & 126 & 145 & 127 & 145 & 113 & 150 & 152 \\
\hline 42 & Title & 153 & 124 & 147 & 127 & 146 & 116 & 153 & 153 \\
\hline 43 & Title & 155 & 128 & 148 & 125 & 148 & 115 & 155 & 154 \\
\hline 44 & Title & 156 & 127 & 152 & 130 & 149 & 119 & 156 & 157 \\
\hline 45 & Title & 157 & 124 & 153 & 131 & 150 & 120 & 157 & 156 \\
\hline 46 & Title & 159 & 128 & 156 & 129 & 152 & 120 & 158 & 156 \\
\hline 47 & Title & 160 & 130 & 157 & 32 & 153 & 121 & 160 & 157 \\
\hline 48 & Title & 161 & 131 & 159 & 135 & 156 & 123 & 161 & 160 \\
\hline 49 & Title & 163 & 132 & 160 & 137 & 157 & 123 & 162 & 163 \\
\hline 50 & Title & 165 & 136 & 163 & 136 & 160 & 125 & 162 & 160 \\
\hline
\end{tabular}

Table 1: All patients' data.

\begin{tabular}{|c|l|l|}
\hline \multicolumn{2}{|c|}{ Unpaired t test } & \\
\cline { 2 - 3 } & & \\
\hline 1 & Table Analyzed & Data 1 \\
\hline 2 & & \\
\hline 3 & Column B & placebo \\
\hline 4 & vs. & vs. \\
\hline 5 & Column A & topiramate \\
\hline 6 & & \\
\hline 7 & Unpaired t test & \\
\hline 8 & P value & 0.0480 \\
\hline 9 & P value summary & \\
\hline 10 & Significantly different $(P<0.05) ?$ & Yes \\
\hline 11 & One- or two-tailed P value? & Two-tailed \\
\hline 12 & t, df & $t=2.003$, df $=98$ \\
\hline 13 & & \\
\hline 14 & How big is the difference? & \\
\hline 15 & Mean of column A & 117.6 \\
\hline 16 & Mean of column B & 126.1 \\
\hline 17 & Difference between means $(B$ - A \pm \pm SEM & $8.510 \pm 4.249$ \\
\hline
\end{tabular}

\begin{tabular}{|l|l|l|}
\hline 18 & $95 \%$ confidence interval & 0.07748 to 16.94 \\
\hline 19 & R squared (eta squared) & 0.03932 \\
\hline 20 & & \\
\hline 21 & F test to compare variances & \\
\hline 22 & F, DFn, Dfd & $1.401,49,49$ \\
\hline 23 & P value & 0.2415 \\
\hline 24 & P value summary & ns \\
\hline 25 & Significantly different (P $<0.05) ?$ & No \\
\hline 26 & & \\
\hline 27 & Data analyzed & \\
\hline 28 & Sample size, column A & 50 \\
\hline 29 & Sample size, column B & 50 \\
\hline
\end{tabular}

Table 2: Topiramate vs placebo shows that topiramate has considerable weight loss effect in comparison to placebo with $p$ value 0.0480 .

The results show that both topiramate and empagliflozine have weight loss effect if used alone with significant $\mathrm{p}$ value which iss 0.0480 with topiramate and 0.0048 in empagliflozine and the greatest weight loss effect if used in combination with $\mathrm{p}$ value less than 0.0001 (Figures 1-11). 


\begin{tabular}{|c|c|c|}
\hline \multicolumn{2}{|r|}{ Unpaired t test } & \\
\hline & & \\
\hline 1 & Table Analyzed & Data 1 \\
\hline \multicolumn{3}{|l|}{2} \\
\hline 3 & Column B & empagliflozine \\
\hline 4 & vs. & vs. \\
\hline 5 & Column A & placebo \\
\hline \multicolumn{3}{|l|}{6} \\
\hline 7 & Unpaired $t$ test & \\
\hline 8 & $P$ value & 0.0048 \\
\hline 9 & $P$ value summary & 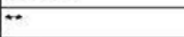 \\
\hline 10 & Significantly different $(P<0.05) ?$ & Yes \\
\hline 11 & One- or two-tailed $P$ value? & Two-tailed \\
\hline 12 & t. $d f$ & $t=2.888, d f=98$ \\
\hline \multicolumn{3}{|l|}{13} \\
\hline 14 & How big is the difference? & \\
\hline 15 & Mean of column A & 126.1 \\
\hline 16 & Mean of column B & 113.4 \\
\hline 17 & Difference between means $(B-A) \pm S E M$ & $-12.69 \pm 4.394$ \\
\hline 18 & $95 \%$ confidence interval & -21.41 to -3.970 \\
\hline 19 & R squared (eta squared) & 0.07843 \\
\hline \multicolumn{3}{|l|}{20} \\
\hline 21 & F test to compare variances & \\
\hline 22 & F, DFn, Dfd & $1.201,49,49$ \\
\hline 23 & $\mathrm{P}$ value & 0.5237 \\
\hline 24 & $P$ value summary & ns \\
\hline 25 & Significantly different $(\mathrm{P}<0.05)$ ? & No \\
\hline \multicolumn{3}{|l|}{26} \\
\hline 27 & Data analyzed & \\
\hline 28 & Sample size, column A & 50 \\
\hline 29 & Sample size, column B & 50 \\
\hline
\end{tabular}

Table 3: Empagliflozine vs placebo shows that empagliflozine has considerable weight loss effect in comparison to placebo with $p$ value 0.0048 .

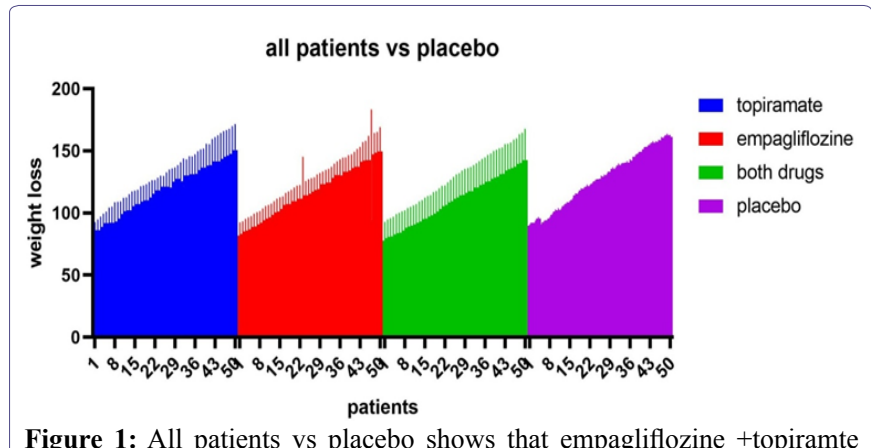

Figure 1: All patients vs placebo shows that empagliflozine +topiramte have the greatest weight loss effect.

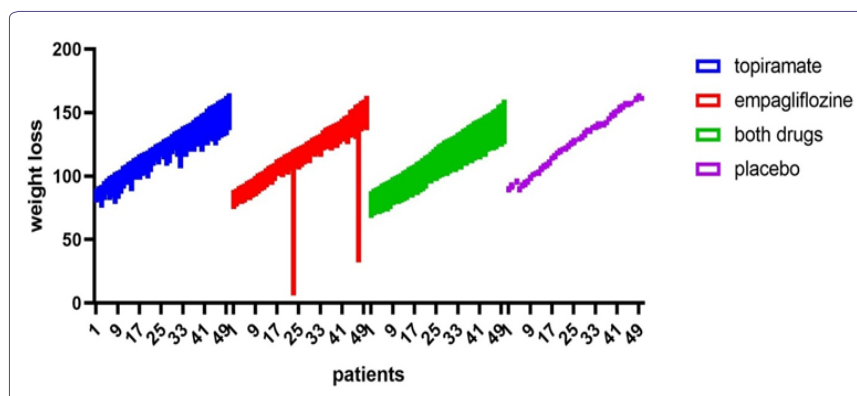

Figure 2: All patients vs placebo shows that empagliflozine +topiramte have the greatest weight loss effect.

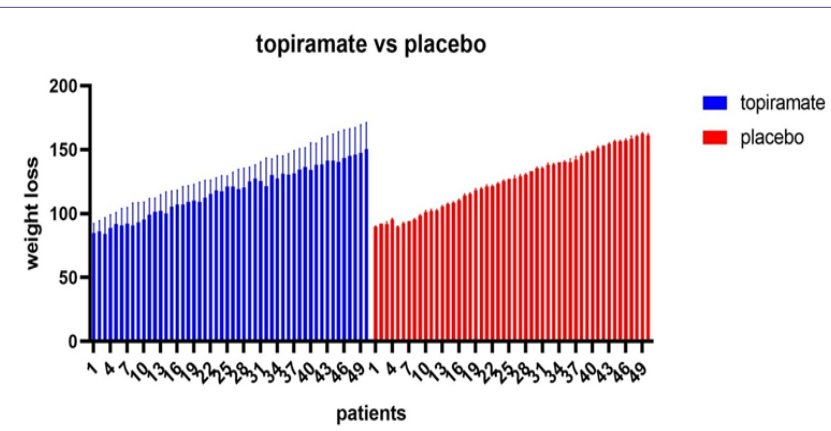

Figure 3: Topiramate vs placebo shows that topiramate has considerable weight loss effect in comparison to placebo with p value 0.0480 .

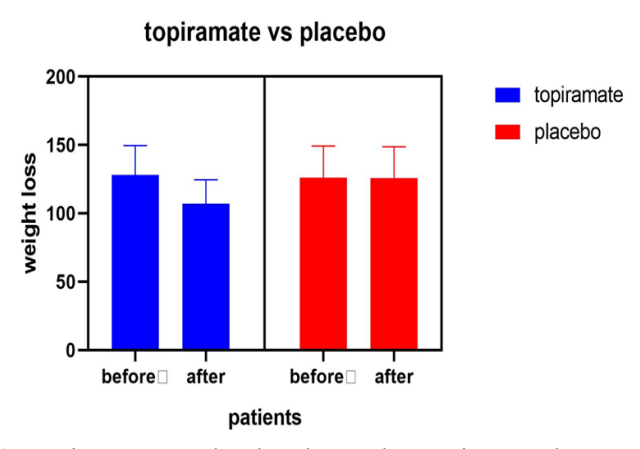

Figure 4: Topiramate vs placebo shows that topiramate has considerable weight loss effect in comparison to placebo with $\mathrm{p}$ value 0.0480 . 


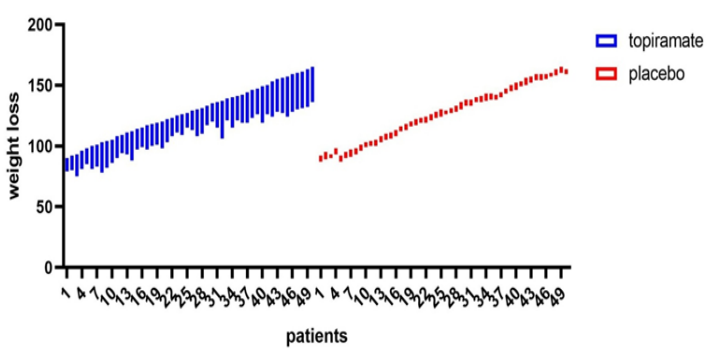

Figure 5: Topiramate vs placebo shows that topiramate has considerable weight loss effect in comparison to placebo with $p$ value 0.0480 .

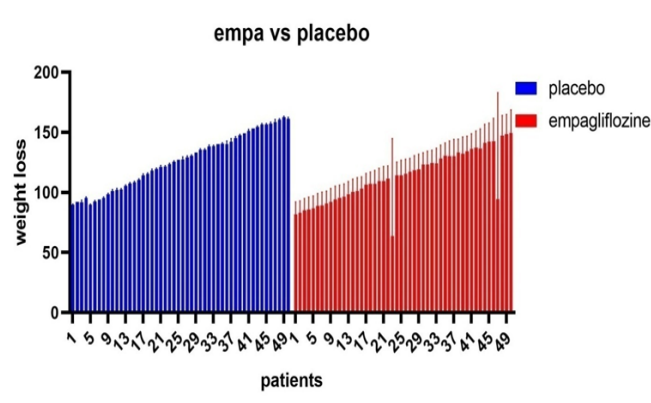

Figure 6: Empagliflozine vs placebo shows that empagliflozine has considerable weight loss effect in comparison to placebo.
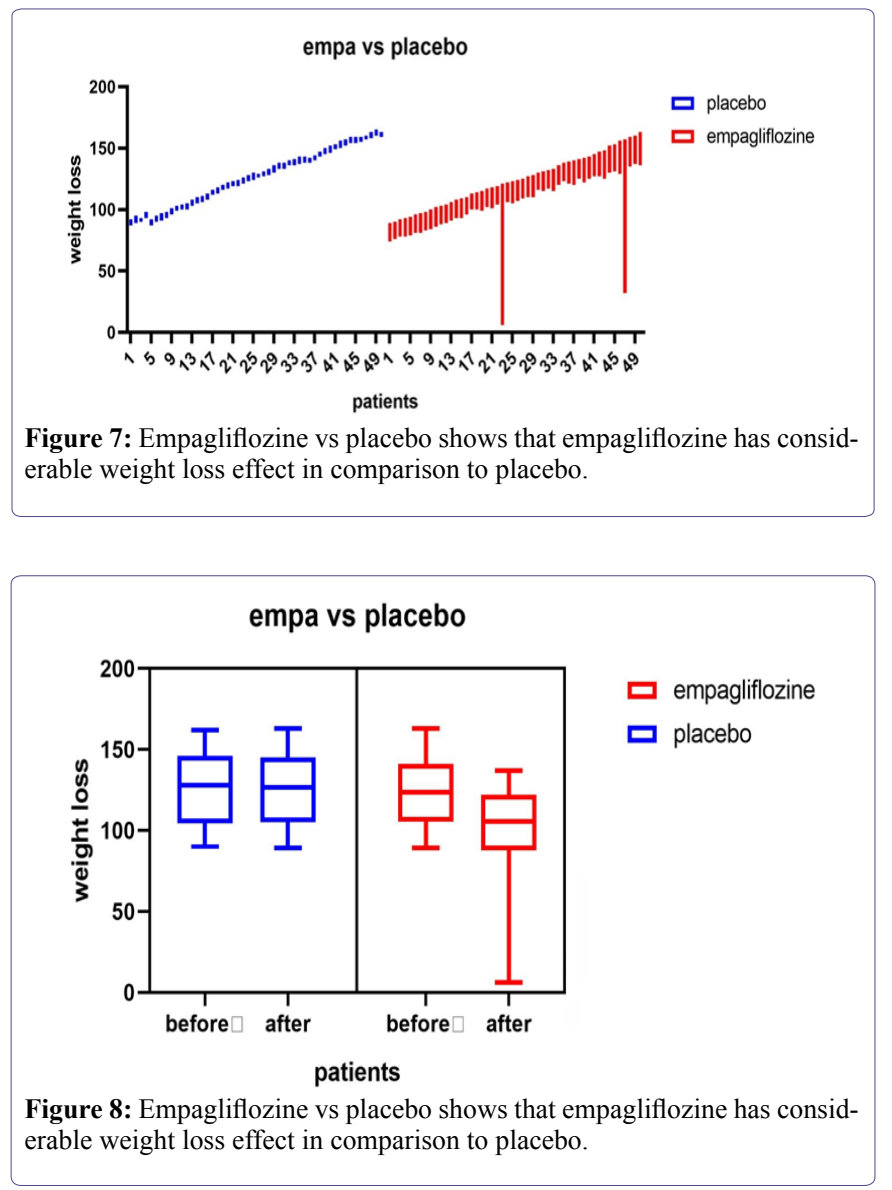

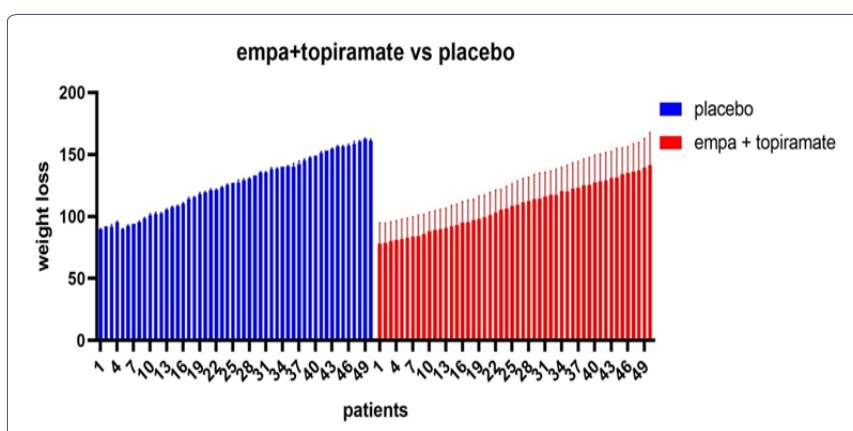

Figure 9: All patients' vs placebo shows that empagliflozine +topiramte have the greatest weight loss effect in comparison to placebo.

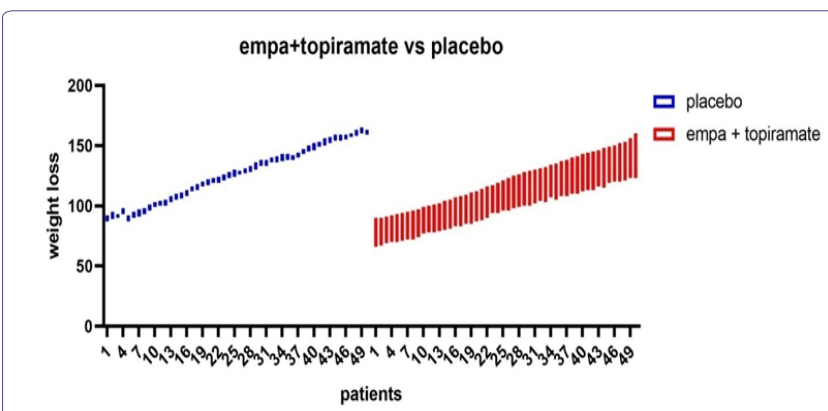

Figure 10: All patients'vs placebo shows that empagliflozine +topiramte have the greatest weight loss effect in comparison to placebo.

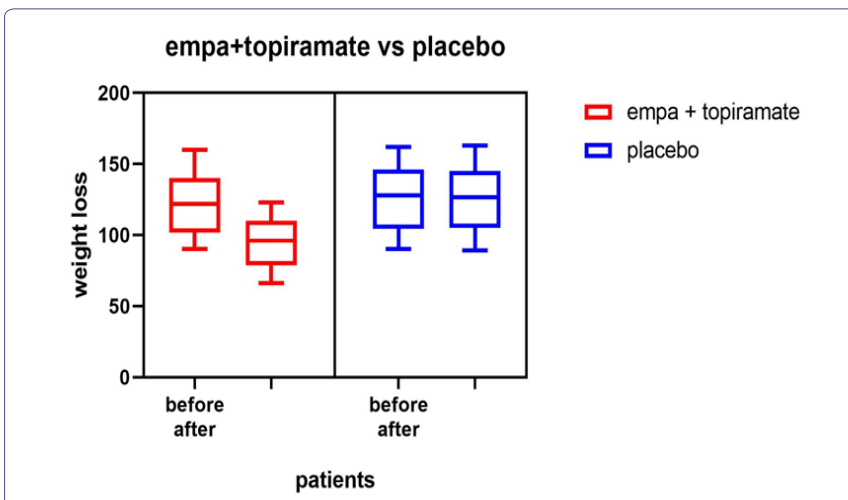

Figure 11: All patients' vs placebo shows that empagliflozine +topiramte have the greatest weight loss effect in comparison to placebo.

\section{Discussion}

There is a great risk of developing diseases and early mortality in patients with obesity, also obesity has a bad effect on the quality of life, by affecting mental and physical health [29]. Wide use of 'Western diet' with high energy all over the world explains the high prevalence of obesity worldwide, not only diet is the culprit also there is a great rule for genetic and epigenetic factors for the occurrence of weight gain [30].

The occurrence of obesity and changes in body weight could be caused by genetic factors, environmental factors or interaction between the 2 factors. also, diet in pregnancy has a considerable effect on DNA methylation that impacts its effect for a long time and 
inherited by upcoming generations [31]. As obesity prevalence increases very much in the last years all over the world and increased health problems related to it, it is a must to develop new ways for the treatment of obesity [32]. Empagliflozin which is the most selective sglt2 inhibitor when compared with placebo leads to great bodyweight reduction with decreasing visceral fat in patients with obesity [33].

Topiramate is a drug which is approved for use in the treatment of epilepsy and migraine, it had a considerable effect on decreasing body weight by reducing calorie input and change in taste [34]. And by comparing topiramate with placebo, there were considerable improvement in blood pressure and in lipid profile with an increase in HDL and a decrease in triglyceride levels [35]. In my trial, combination of topiramate and empagliflozine results in considerable decrease in weight compared to each drug alone and compared to placebo.

The restriction of my study is the few patients sample size. While the inclusion of a small number of patients limits and restricts the extrapolation of our findings to the general population, obesity is a serious health problem, and my study aims to find a new treatment option for obesity. My findings in this study indicate that combination of topiramate and empagliflozine is a potential treatment for obesity by decreasing body weight, visceral obesity and improving lipid profile. Further large-scale studies and clinical trials are required to confirm our results.

\section{Conflicts of Interest}

uthors declared that there is no conflict of Interest.

\section{Conclusion}

As obesity prevalence increases very much worldwide, there is an urgent need to discover a new treatment option for diabetes to control this epidemic. Now, there are many approved drugs for obesity, but maximal body weight reduction is about $5 \%$.Combination of drugs is considered as an optimal option for the treatment of diabetes. Combination of topiramate and empagliflozin show a considerable reduction of body weight and so is considered as an option for treatment of obesity.

\section{References}

1. Chooi Yu, Ding C, Magkos F (2019) The epidemiology of obesity. Metabolism-Clinical and Experimental 92: 6-10

2. World Health Organization. Obesity and overweight (2015).

3. Swinburn BA, Sacks G, Hall KD, McPherson K, Finegood DT, et al., (2011) The global obesity pandemic: shaped by global drivers and local environments. Lancet 378: 804-814.

4. Davison KK, Birch LL (2001) Childhood overweight: A contextual model and recommendations for future research. Obes Rev 2: 159-171.

5. Anderson PM, Butcher KE (2006) Childhood obesity: Trends and potential causes. Future Child 16: 19-45.

6. Political declaration of the third high-level meeting of the general assembly on the prevention and control of non-communicable diseases (2018). WHO.

7. Franco M, Bilal U, Orduñez P, Benet M, Morejon A, et al., (2013) Population-wide weight loss and regain in relation to diabetes burden and cardiovascular mortality in Cuba 1980-2010: Repeated cross sectional surveys and ecological comparison of secular trends. BMJ 346: 1515.
8. Heymsfield SB, Wadden TA (2017) Mechanisms, pathophysiology, and management of obesity. N Eng J Med 376: 254-266.

9. Matthias B (2019) Obesity: Global epidemiology and pathogenesis. Nature Reviews Endocrinology 15: 288-298.

10. Berthoud HR, Münzberg H, Morrison CD (2017) Blaming the brain for obesity: integration of hedonic and homeostatic mechanisms. Gastroenterology 152: 1728-1738.

11. Srivastava G, Apovian CM (2018) Current pharmacotherapy for obesity. Nat Rev Endocrinol 14: 12-24.

12. Singh AK, Unnikrishnan AG, Zargar AH, Kumar A, Das AK, et al., (2019) Evidence-Based Consensus on Positioning of SGLT2i in Type 2 Diabetes Mellitus in Indians. Diabetes Ther 10: 393-428.

13. Mather A, Pollock C (2011) Glucose handling by the kidney. Kidney Int Suppl 120: 1-6.

14. Neumiller JJ (2014) Empagliflozin: A new sodium-glucose co-transporter 2 (SGLT2) inhibitor for the treatment of type 2 diabetes. Drugs Context 3: 212262

15. Jardiance 10 and $25 \mathrm{mg}$ film-coated tablets: summary of product characteristics. European Medicines Agency (2018).

16. Chan HW, Ashan B, Jayasekera P, Collier A, Ghosh S (2012) A new class of drug for the management of type 2 diabetes: sodium glucose co-transporter inhibitors: 'glucuretics'. Diabetes Metab Syndr 6: 224-228.

17. Hach T, Lambers Heerspink HJ, Pfarr E (2012) The sodium glucose cotransporter-2 (SGLT-2) inhibitor empagliflozin lowers blood pressure independent of weight or HbA1c changes. Diabetologia 55: 317.

18. Hendricks EJ (2017) Off-label drugs for weight management. Diabetes Metab Syndr Obes 10: 223-234.

19. Ritchey ME, Harding A, Hunter S, Peterson C, Sager PT, et al., (2019) Cardiovascular Safety During and After Use of Phentermine and Topiramate. J Clin Endocrinol Metab 104: 513-522.

20. Antel J, Hebebrand J (2012) Weight-reducing side effects of the antiepileptic agents topiramate and zonisamide. Handb Exp Pharmacol 209: 433-466.

21. Berlant J, Van Kammen DP (2002) Open-label topiramate as primary or adjunctive therapy in chronic civilian posttraumatic stress disorder: A preliminary report. J Clin Psychiatry 63: 15-20.

22. Claudino AM, De Oliveira IR, Appolinario JC, Cordas TA, Duchesne M, et al., (2007) Double-blind, randomized, placebo-controlled trial of topiramate plus cognitive-behavior therapy in binge-eating disorder. J Clin Psychiatry 68: 1324-1332.

23. Rosenstock J, Hollander P, Gadde KM, Sun X, Strauss R, et al., (2007) A randomized, double-blind, placebo-controlled, multicenter study to assess the efficacy and safety of topiramate controlled release in the treatment of obese type 2 diabetic patients. Diabetes Care 30: 1480-1486.

24. Blevins D, Wang XQ, Sharma S, Ait-Daoud N, (2019) Impulsiveness as a predictor of topiramate response for cocaine use disorder. Am J Addict 28: 71-76.

25. York DA, Singer L, Thomas S, Bray GA (2000) Effect of topiramate on body weight and body composition of Osborne-Mendel rats fed a highfat diet: Alterations in hormones, neuropeptide, and uncoupling-protein mRNAs. Nutrition 16: 967-975.

26. Richard D, Ferland J, Lalonde J, Samson P, Deshaies Y, et al., (2000) Influence of topiramate in the regulation of energy balance. Nutrition 16: 961-966.

27. Greenwood RS (2000) Adverse effects of antiepileptic drugs. Epilepsia 4: 42-51. 
28. Kolotkin RL, Andersen JR (2017) A systematic review of reviews: exploring the relationship between obesity, weight loss and health-related quality of life. Clin Obes 7: 273-289.

29. Organization for Economic Co-operation and Development. Obesity Update (2017).

30. Panzeri I, Pospisilik JA (2018) Epigenetic control of variation and stochasticity in metabolic disease. Mol. Metab 14: 26-38.

31. Srivastava G, Apovian C (2018) Future Pharmacotherapy for Obesity: New Anti-obesity Drugs on the Horizon. Curr Obes Rep 7: 147.
32. Neeland IJ, McGuire DK, Chilton R, Crowe S, Lund SS, et al., (2016) Empagliflozin reduces body weight and indices of adipose distribution in patients with type 2 diabetes mellitus. Diab Vasc Dis Res 13: 119-126.

33. Wilding J, van Gaal L, Rissanen A, Vercruysse F, Fitchet M (2004) A randomized double-blind placebo-controlled study of the long-term efficacy and safety of topiramate in the treatment of obese subjects. Int J Obes Relat Metab Disord 28: 1399-1410.

34. Kumar RB, Aronne LJ (2000) Pharmacologic Treatment of Obesity. Endotext [Internet]. 


\section{Hit \\ ндтар}

Journal of Anesthesia \& Clinical Care

Journal of Addiction \& Addictive Disorders

Advances in Microbiology Research

Advances in Industrial Biotechnology

Journal of Agronomy \& Agricultural Science

Journal of AIDS Clinical Research \& STDs

Journal of Alcoholism, Drug Abuse \& Substance Dependence

Journal of Allergy Disorders \& Therapy

Journal of Alternative, Complementary \& Integrative Medicine

Journal of Alzheimer's \& Neurodegenerative Diseases

Journal of Angiology \& Vascular Surgery

Journal of Animal Research \& Veterinary Science

Archives of Zoological Studies

Archives of Urology

Journal of Atmospheric \& Earth-Sciences

Journal of Aquaculture \& Fisheries

Journal of Biotech Research \& Biochemistry

Journal of Brain \& Neuroscience Research

Journal of Cancer Biology \& Treatment

Journal of Cardiology: Study \& Research

Journal of Cell Biology \& Cell Metabolism

Journal of Clinical Dermatology \& Therapy

Journal of Clinical Immunology \& Immunotherapy

Journal of Clinical Studies \& Medical Case Reports

Journal of Community Medicine \& Public Health Care

Current Trends: Medical \& Biological Engineering

Journal of Cytology \& Tissue Biology

Journal of Dentistry: Oral Health \& Cosmesis

Journal of Diabetes \& Metabolic Disorders

Journal of Dairy Research \& Technology

Journal of Emergency Medicine Trauma \& Surgical Care

Journal of Environmental Science: Current Research

Journal of Food Science \& Nutrition

Journal of Forensic, Legal \& Investigative Sciences

Journal of Gastroenterology \& Hepatology Research

Journal of Gerontology \& Geriatric Medicine
Journal of Genetics \& Genomic Sciences

Journal of Hematology, Blood Transfusion \& Disorders

Journal of Human Endocrinology

Journal of Hospice \& Palliative Medical Care

Journal of Internal Medicine \& Primary Healthcare

Journal of Infectious \& Non Infectious Diseases

Journal of Light \& Laser: Current Trends

Journal of Modern Chemical Sciences

Journal of Medicine: Study \& Research

Journal of Nanotechnology: Nanomedicine \& Nanobiotechnology

Journal of Neonatology \& Clinical Pediatrics

Journal of Nephrology \& Renal Therapy

Journal of Non Invasive Vascular Investigation

Journal of Nuclear Medicine, Radiology \& Radiation Therapy

Journal of Obesity \& Weight Loss

Journal of Orthopedic Research \& Physiotherapy

Journal of Otolaryngology, Head \& Neck Surgery

Journal of Protein Research \& Bioinformatics

Journal of Pathology Clinical \& Medical Research

Journal of Pharmacology, Pharmaceutics \& Pharmacovigilance

Journal of Physical Medicine, Rehabilitation \& Disabilities

Journal of Plant Science: Current Research

Journal of Psychiatry, Depression \& Anxiety

Journal of Pulmonary Medicine \& Respiratory Research

Journal of Practical \& Professional Nursing

Journal of Reproductive Medicine, Gynaecology \& Obstetrics

Journal of Stem Cells Research, Development \& Therapy

Journal of Surgery: Current Trends \& Innovations

Journal of Toxicology: Current Research

Journal of Translational Science and Research

Trends in Anatomy \& Physiology

Journal of Vaccines Research \& Vaccination

Journal of Virology \& Antivirals

Archives of Surgery and Surgical Education

Sports Medicine and Injury Care Journal

International Journal of Case Reports and Therapeutic Studies

Journal of Ecology Research and Conservation Biology

Submit Your Manuscript: http://www.heraldopenaccess.us/Online-Submission.php 